\title{
Analysis of a kind of bearing capacity of reinforced concrete hollow pillar compression and construction application mode
}

\author{
Hejun Xu, Fan Zhu, Yuhui Wang, Chuxian Zhang, Xi Han \\ The School of Civil Engineering, Shenyang Jianzhu University, Liaoning Shenyang 110168
}

\begin{abstract}
Keyword: Reinforced concrete hollow pillar ; The compressive bearing capacity ; Construction application
\end{abstract}

\begin{abstract}
This article introduces a kind of reinforced concrete hollow pillar, the pillar with hollow beam and column composed of reticular cells, each mesh cell in the horizontal direction through the telescopic column connection, in the vertical direction through the internal screw sleeve connection, terminal in the reticular cells in horizontal direction through the elbow connection pipe is connected with the telescopic rod is matched by a positioning pin through, upright positioning hole on the pin connected with the template. The pillar of reticular cells can be combined arbitrarily in the horizontal direction and the vertical direction, the hollow pillar according to the construction size requirements to good combination reticular cells form, with the template will be pouring concrete inside the template, can be installed through the lifting device at the top of the upright post of the whole mechanism to lift the mobile, reduced the construction equipment covers an area of, shorten the building time, easy to move, can complete the construction without support. At the same time, through the contrast calculation, the pillar of compressive bearing capacity calculation formula of good, can be extended.
\end{abstract}

\section{Hollow pillar Exposition}

\subsection{The technical background}

Reinforced concrete hollow slab has It is often seen. in architectural field. This kind of structure stress mainly concentrated in the flange, while in the neutral axis is close to zero. So, we take advantage of this feature, the structure is made into a hollow board. One is to save materials, reduce the project cost; and can reduce the weight of structure, reducing the load on the structure, convenient construction operation. ${ }^{[1]}$

However, often reinforced concrete hollow slab structures is time-consuming and laborious, the building covers an area of a lot, the pillar structure leg and bracket are often time-consuming and hinge plate fixed height not according to the size of the architecture independent regulation, transport and construction schedule construction equipment, wall with same size cement pouring construction and demolition work must be completed, consuming human and material resources.

\subsection{The content and structure}

Technical problems of the novel hollow pillars to be solved, is to address the above problems of technology, provides a reinforced concrete hollow pillar, the beam and column composed of reticular cells, each mesh cell in the horizontal direction through the telescopic column connection, in the vertical direction through the internal screw sleeve connection, terminal in the reticular cell level the direction of the connecting pipe through the elbow is connected with a telescopic rod with, through a positioning pin through the positioning holes and the pin column template on the ground, reticular cells can be combined arbitrarily in the horizontal direction and the vertical direction, the hollow pillar according to construction requirements to the combination of good mesh size cells form, with the template will be pouring concrete inside the template, you can through the installation of the lifting device at the top of the upright post of the whole mechanism to lift the mobile, reduced the construction equipment covers an area of, shorten the plumber, mobile convenience, good equipment can be completed without support construction $^{[2]}$. In order to solve the technical problem, the technical proposal of the utility model is used: including the mesh cell, a telescopic column, a telescopic rod, lifting de- 
vice, template, double connecting column, each mesh cell horizontally connected with the telescopic column screw thread, and each mesh cell in the vertical direction and the internal thread casing thread connection; double column connection one end is connected with a telescopic rod, the other end is connected with the elbow pipe thread connection; elbow connection pipe in the horizontal direction is connected with the reticular cell threads; hoisting device connected through the internal thread bushing and the reticular cell thread in the vertical direction; each template and each mesh cell in the horizontal direction pin.

Reticular cell comprises two cross beams and two columns and two beams of two upright posts in the horizontal direction and the vertical direction of the vertical welding; the middle part of each column in the perpendicular to the reticular cell plane is provided with a positioning hole and the positioning hole and the positioning pin matched with the through the column of the template for the pin connection. The lifting device comprises a davit and rings, the rings through the upper end and the lower end of the davit davit, the upper end of the upright post connecting thread ${ }^{[3]}$.

Compared with the prior art, the utility model has the following advantages: splicing hollow pillar 1 , reticular cell according to the construction size requirements from the main regulating reticular cells assembled into the mold surface, match template can be built in accordance with construction dimensions of the mechanism; 2, lifting device is arranged on the upper end of the vertical beam, can be poured with a size of the wall without disassembly, directly through the mechanism of integral lifting, the utility model is positioned to the construction of the specified location, to avoid the need to disassemble each time you use the trouble, and saves time and area, saves construction cost.

\subsection{Hollow pillar structure design}
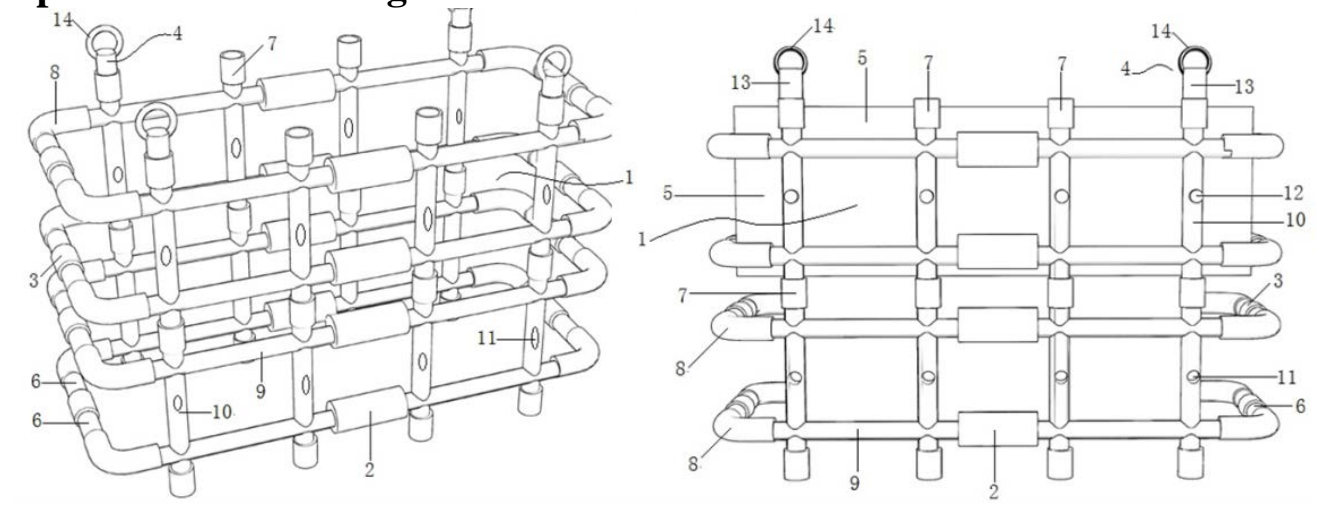

\section{Analysis of bearing capacity of hollow pillar}

\subsection{Axial compressive capacity of the hollow pillar}

For concrete columns, experiments show that, when the increase of slenderness ratio, the destruction shape hollow pillar by pillar of material damage will be gradually to the instability and failure of transformation. Thus, according to the actual experiment, the calculation of the axial compressive bearing capacity, the need to introduce a characterization $\theta_{l}$, which characters the slenderness ratio thinner than the reduction coefficient, to calculate the axial compressive bearing capacity of the hollow pillar: $N_{l}$.I.e.:

$$
N_{l}=\theta_{l} N=\theta_{l}\left[2 b \pi t^{2} f_{y}+\frac{\pi\left(D_{0}^{2}-d^{2}\right)}{4}\left(f_{c}+k \frac{2 t}{D} f_{y}\right)\right]_{[4]}
$$

Among: Expressions for the $\theta_{l}: \theta_{l}=1-0.115 \sqrt{L / D-4}$ 。

\subsection{Analysis and calculation of verification and comparison}

By comparing the data of the actual experiment and literature, we can know the bearing capacity 
of the hollow pillar compression. Through the long column specimen test data of [7],the results were compared with the above formula. As shown in table 1.

table 1 Axial compression hollow long column specimen test results contrast calculation table

\begin{tabular}{|c|c|c|c|c|}
\hline numbers & $\begin{array}{l}\text { The size of the steel tube } \\
\qquad \begin{array}{c}D \times t \times L \\
(\mathrm{~mm})\end{array}\end{array}$ & $\mathrm{d}(\mathrm{mm})$ & $\begin{array}{c}\text { slenderness ratio } \\
\lambda\end{array}$ & $\begin{array}{c}\text { The uniaxial } \\
\text { compressive } \\
\text { strength of concrete } \\
f_{c}(\mathrm{MPa})\end{array}$ \\
\hline $1-1$ & $300 \times 3 \times 3000$ & 217 & 34 & 25.3 \\
\hline $1-2$ & $300 \times 3 \times 3000$ & 213 & 34 & 25.3 \\
\hline $2-1$ & $300 \times 3 \times 4000$ & 245 & 45 & 25.3 \\
\hline $2-2$ & $300 \times 3 \times 4000$ & 243 & 45 & 25.3 \\
\hline $3-1$ & $300 \times 3 \times 3000$ & 176 & 40 & 25.3 \\
\hline $3-2$ & $300 \times 3 \times 3000$ & 171 & 40 & 25.3 \\
\hline $\begin{array}{r}\text { Steel } \\
\text { yield strength } \\
f_{y}(\mathrm{MPa})\end{array}$ & \multicolumn{3}{|c|}{ Ultimate bearing capacityN } & \\
\hline & \multirow{2}{*}{ The measured values } & \multirow{2}{*}{$\begin{array}{l}\text { The meas- } \\
\text { ured values }\end{array}$} & \multicolumn{2}{|c|}{ The calculated values } \\
\hline & & & \multicolumn{2}{|c|}{ The measured values } \\
\hline 350.1 & 1351 & 1494.52 & \multicolumn{2}{|c|}{1.106} \\
\hline 51350.1 & 1307 & 1507.56 & \multicolumn{2}{|c|}{1.153} \\
\hline 350.1 & 1235 & 1096.65 & \multicolumn{2}{|c|}{0.888} \\
\hline 350.1 & 1153 & 1058.57 & \multicolumn{2}{|c|}{0.918} \\
\hline 350.1 & 1967 & 2117.19 & \multicolumn{2}{|c|}{1.076} \\
\hline 350.1 & 2060 & 2109.01 & \multicolumn{2}{|c|}{1.024} \\
\hline
\end{tabular}

As can be seen, formula derived from this method has strong reliability, the calculating value is accurate. The compressive strength of hollow pillar with bearing capacity requirements ${ }^{[5]}$.

\section{Hollow pillar construction application methods}

With 1.3 illustrations, to this kind of reinforced concrete hollow pillar do construction on the application $^{[6]}$.

Hollow pillar includes a mesh cell 1, telescopic column 2, telescopic rod 3, lifting 4, 5 template, double connection column 6, each mesh cell on a horizontal connection with telescopic column 2 thread, and each 7 screwed on the mesh cell 1 in the vertical direction and the inner threaded sleeve; column 6 is connected one end of the stud 3 is connected to the telescopic rod, and the other end is connected with the elbow pipe 8 threaded connection; elbow connection pipe 8 in the horizontal direction a threaded connection with the mesh cell; lifters 471 through the inner threaded sleeve threaded connection with the mesh cell in the vertical direction ${ }^{[7]}$; each template 5 with each mesh cell 1 in the horizontal direction pinned ; mesh cell 1 comprises two beams 9 and two uprights 10, the two beams 9 and 10 vertically welded on the two columns in the vertical direction in the horizontal direction; the middle of each column 10 is perpendicular to the mesh unit opened a positioning hole 11, the positioning hole 11 and the positioning pin 12 through the uprights with 10 pairs of template 5. pinned on a plane lattice; lifting davit 4 includes 13 and 14 rings, 14 rings throughout 
the 13 upper davits, davit the lower end of the upper end of the column 1013 threaded connections ${ }^{[8]}$.

When it is used, determined according to the size of building construction size of the institution, through the mesh of the beam on a 9-cell connection telescopic column 2, by adjusting the telescopic two dimensions of this body in the longitudinal direction, and on through the mesh cell 1 column 10 , column 10 is connected internally threaded bushing 7 the height adjustment of the mechanism in the vertical direction, through the end of the tube 8 is connected to the elbow connector beams 9, elbow connection pipe 8 through the connection stud and the telescopic rod 6 connecting posts 4 , this means adjusting the size in the width direction, without the support frame and other auxiliary equipment, construction cost savings, reducing the footprint, the template 5 through the positioning pins 12 through the positioning holes 10 on the post 11 , the template 5 pin connected to the column 10 , thus completing the rapid build of the body; when construction needs another pouring concrete block wall, it will be installed in the top 4 lifting columns 10, 13 and the inner davit tighten the threaded bushing 7, the rope socket 14 on the rings, lifting in the vertical direction of the body, move it to a location designated construction, complete fast-moving work, no longer separate structures, each use to avoid the trouble of disassembly required, saving hours of work and footprint, saving the cost of construction, to the design effect ${ }^{[9][10]}$.

\section{Conclusions}

1. This kind of reinforced concrete hollow pillar can basically solve some of the problems of the prior art, is simple to operate, reducing the amount of construction and so on.

2. The types of reinforced concrete hollow pillar has more good compression capacity, to meet the construction requirements of the force. While the bearing capacity of the hollow pillar provides a new calculation formula.

3. The kind of hollow concrete pillar construction process is simple, no longer separate structures, each use to avoid the trouble of disassembly required, saving hours and footprint, save construction cost, to the design effect ${ }^{[11]}$.

\section{References}

[1] [1] Song Pu "modern concrete basic theory and engineering applications" [M]. China Architectural Press 2008

[2] [2] for ultimate, Song Pu "reinforced concrete structure" Mechanical Press [M] .2004

[3] [3] Wang Licheng, for ultimate, Pu Song "Hydraulic Reinforced Concrete Structures" Mechanical Press [M] .2008

[4] [4] "reinforced concrete structure design specifications" ］S].GB50010-2010

[5] [5] MIYAKI SATOSH. Evalution formular of compressive strength of centrifugal concrete filled steel square tubular columns[J]. Kozo Kogaku Ronbunshu.B.Journal of Structural Engineering. B), 1997, 43B:581-586.

[6] [6] MIYAKI SATOSH. Ultimate strength and deformation capacity of centrifugal concrete filled steel square tubular columns[J].Nippon Kenchiku Gakkai Kozokei Ronbunshu (Journal of Structural and Construction Engineering)(Transactions of AIJ), 1997(500):105-112.

[7] [7] O'Shea M.D., Bridge R.Q., Test on circular thin-walled steel tubes filled with medium and high strength concrete[J]. Research Report- University of Sydney, Department of Civil Engineering, 1997(755):1- 118.

[8] [8] Zhong Shantong, Xu Guolin, hollow concrete filled steel tube under axial compression performance [J] Journal of Harbin Institute of Technology, 2006,9 (38): 1479-1503.

[9] [9] Wang Hongwei, IN STEEL experimental study of hollow concrete filled steel tube long columns under axial compression [J]. Industrial buildings, 2006,36 (12): 69-73.

[10][10] Cai Shaohuai modern steel concrete structures [M]. Beijing: China Communications Press, 2003. 
[11][11] Dou Haojie, Xiao Peng, Liu Lili. Prevention and Treatment of large diameter hollow cylinder surface defects in concrete [J]. Real Estate Guide, 2014, (2) 